\title{
VEINTICINCO AÑOS DE OPINIÓN PÚBLICA SOBRE LA DEMOCRACIA, LA CONSTITUCIÓN Y LAS INSTITUCIONES ESPAÑOLAS
}

\author{
JUAN ANDRÉS MUÑOZ ARNAU \\ Profesor Titular de Derecho Constitucional \\ Universidad de La Rioja
}




\section{SUMARIO}

I. Introducción. II. El Público opinante. III. El sistema educativo y los MEDIOS DE COMUNICACIÓN EN LA FORMACIÓN DE LA CULTURA POLITICA. IV. CONOCIMIENTOS, VALORACIONES Y ACTITUDES DE LOS ESPAÑOLES: 1. El Régimen político anterior. 2. La transición política. 3. El Estado, la democracia y la participación política. 4. La Constitución. 5. Las instituciones de gobierno generales. 5.1. La Corona. 5.2. Las Cortes Generales. 5.3. El Gobierno de la Nación. 5.4. El Poder Judicial. 5.5. El Tribunal Constitucional. 6. Las instituciones autonómicas y locales 7. Las instituciones sociales. 7.1. Los partidos políticos. 7.2. Los sindicatos. 7.3. Las empresas. 8. Los problemas sociales. VI. A MODO DE CONCLUSIÓN. 


\title{
VEINTICINCO AÑOS \\ DE OPINIÓN PÚBLICA \\ SOBRE LA DEMOCRACIA, LA CONSTITUCIÓN \\ Y LAS INSTITUCIONES ESPAÑOLAS
}

\author{
POR \\ JUAN ANDRÉS MUÑOZ ARNAU \\ Profesor Titular de Derecho Constitucional \\ Universidad de La Rioja
}

\section{INTRODUCCIÓN}

Quizás no sea ocioso incluir entre los trabajos jurídico-constitucionales que se recogen en este volumen, uno que tenga que ver con la percepción que los ciudadanos han ido teniendo de la democracia, de la Constitución, de las distintas instituciones de gobierno y de los problemas que les ha tocado vivir a lo largo de estos años y a los que de alguna manera la Constitución debería haber dado respuesta. En definitiva, intentar una aproximación a los conocimientos, actitudes y valoraciones de los españoles ante la realidad política.

Seguramente las conclusiones que se obtengan no diferirán mucho de las que pueda llegar a establecer cada uno si la edad le ha hecho testigo desapasionado - $y$ benévolo- de este ya apreciable periodo de tiempo, aunque la vida de las instituciones tenga un tiempo diferente al de las personas de carne $y$ hueso. 
Se trata de ofrecer un panorama general de estos 25 años - que no puede ser por ello detallado y profundo- a través de las conclusiones que se pueden obtener de algunas encuestas que a lo largo de este tiempo ha publicado el CIS'. La consideración de los datos par-

1 El art. 1. del Real Decreto núm. 1214/1997 de 18-7-1997, (BOE 22-7-1997) que desarrolla, la ley núm. 39/1995, de 19-12-1995 define el Centro de Investigaciones Sociológicas como un organismo autónomo de los previstos en el artículo 43.1, a), de la Ley 6/1997, de 14 de abril, de Organización y Funcionamiento de la Administración General del Estado, con personalidad jurídica y patrimonio propios, adscrito administrativamente al Ministerio de la Presidencia, que tiene por finalidad el estudio científico de la sociedad española.

Su actuación se rige, además de por las leyes y disposiciones generales que le sean de aplicación, por la Ley 39/1995, de 19 de diciembre, de Organización del Centro de Investigaciones Sociológicas; por la Ley 6/1997, de 14 de abril, de Organización y Funcionamiento de la Administración General del Estado; por la Ley General Presupuestaria, texto refundido aprobado por Real Decreto Legislativo 1091/1988, de 23 de septiembre, así como por el Real Decreto indicado más arriba y sus normas de desarrollo.

Sus principios de actuación recogidos en el art. 2 de este Decreto son los de objetividad y neutralidad en su actuación, de igualdad de acceso a sus datos y de respeto a los derechos de los ciudadanos y al secreto estadístico. Entre las funciones indicadas en el art. 3 tienen una mayor relevancia política las siguientes: a) La programación, diseño y realización de estudios que contribuyan al conocimiento científico de la sociedad española, principalmente mediante la ejecución de las encuestas que sean necesarias para llevar a cabo dichos estudios; b) La programación, diseño y realización de estudios que contribuyan al conocimiento científico de la realidad social de las diferentes Comunidades Autónomas, cuando proceda, mediante la suscripción por el centro, de los oportunos convenios de cooperación con las mismas; c) La realización de estudios que proporcionen diagnósticos sobre situaciones y asuntos sociales y sirvan de orientación a los poderes públicos en sus iniciativas normativas y ejecutivas; d) La creación y mantenimiento de bases de datos en las materias de su competencia.

Es de interés señalar los principios de actuación las investigaciones realizadas mediante encuesta recogidas en el art. 5: a) Voluntariedad de las respuestas, en especial cuando se inquiera acerca de cuestiones de tipo étnico, político, religioso, ideológico o que se refieran a la intimidad personal o familiar. b) Transparencia investigadora, informando a los encuestados respecto del organismo que realiza el estudio y la naturaleza y finalidad de éste, así como de las garantias que les asisten en relación a la protección de su identidad e intimidad. c) Especialidad, utilizando la información para las finalidades propias de la investigación y siempre dentro de los objetivos del centro. d) Protección de los datos personales, adoptando, en cualquier fase del proceso de investigación y con posterioridad al mismo, las medidas necesarias para garantizar el derecho a la privacidad e intimidad de individuos y familias, por el presente Real Decreto y sus normas de desarrollo.

Existe la obligación por parte del Presidente del Centro de elevar cada tres meses al Congreso de los Diputados y al Senado, por conducto de sus respectivos Presidentes, y a través del Ministerio de la Presidencia, la relación circunstancia- 
ciales de unas cuantas encuestas a lo largo de este tiempo sólo puede conducir a una aproximación a la que podrían oponerse con toda legitimidad otras basadas en los mismos datos o en otros que pudieran escogerse. Los resultados de una encuesta son siempre una impresión momentánea de una realidad siempre cambiante. $Y$ no menos impresionista será una visión que -como ésta - se basa en unos pocos datos de entre la enormidad que el CIS ha acumulado durante estos años.

No se cuestionan aquí ni la independencia de ese organismo público ni la cientificidad de los métodos empleados para alcanzar los resultados ofrecidos. Se dan por supuestos una y otros. Únicamente interesan los datos que resultan de una actividad que entendemos se ejerce con criterios profesionales.

Me ha parecido conveniente dividir este trabajo en dos partes. La primera, dedicada a considerar algunas dimensiones básicas del público opinante que ayudarán a valorar sus afirmaciones acerca de los objetos sobre los que se les preguntó. La segunda, articulada alrededor de las distintas cuestiones sobre las que se ha pedido opinión

da de los trabajos finalizados e ingresados en su banco de datos. Asimismo, cuando alguno de los trabajos incluidos en la relación tuviere como ámbito territorial el de una o más Comunidades Autónomas, el Presidente del centro lo pondrá simultáneamente en conocimiento de la Asamblea o Asambleas legislativas de la Comunidad o Comunidades Autónomas correspondientes, por conducto de sus respectivos Presidentes, y a través del Ministerio de la Presidencia (art. 6.6).

Además se prevé el acceso a los datos por parte de Diputados y Senadores para el mejor cumplimiento de sus funciones, conforme a lo establecido en los Reglamentos del Congreso de los Diputados y del Senado para la obtención de datos de las Administraciones públicas (art. 8). El art. 9 establece en relación con los datos de carácter electoral y político que el Presidente del Centro de Investigaciones Sociológicas remitirá al Congreso de los Diputados y al Senado, por conducto de sus respectivos Presidentes, y a través del Ministerio de la Presidencia, un avance provisional de los resultados de sus encuestas que se refieran a intención de voto, valoración de partidos y valoración de líderes políticos. Dichos avances provisionales se remitirán en un plazo no superior a quince días a contar de la fecha de finalización de los trabajos de campo y de la codificación y grabación de la información en soporte magnético. Si la encuesta tuviere como ámbito territorial el de una o más Comunidades Autónomas, el avance provisional de resultados será remitido por el Presidente del Centro a la Asamblea o Asambleas legislativas de la Comunidad o Comunidades Autónomas correspondientes, por conducto de sus respectivos Presidentes, y a través del Ministerio de la Presidencia.

El número 1 de la REIS es de enero-marzo de 1978. La revista está vinculada al nacimiento de la España democrática. 
y que me han parecido más relevantes por traducir conocimientos, juicios de valor y actitudes de relevancia política. Las cuestiones a que me refiero son:

a) Régimen político anterior

b) La transición política

c) El Estado, la democracia y la participación política

d) La Constitución

e) Las instituciones de gobierno

1. Generales

\subsection{La Corona}

1.1. Las Cortes Generales

1.1. El Gobierno de la Nación

1.1. El Poder Judicial

1.1. ElTribunal Constitucional

2. Autonómicas y Locales

f) Las instituciones sociales

1. Los partidos políticos

2. Los sindicatos

2. Las empresas

g) Los problemas sociales

Bien se ve que un espectro de cuestiones tan amplio sólo puede ser abordado en términos muy generales, puesto que ni siquiera podrían tomarse en consideración una parte de las encuestas en las que se ha preguntado sobre cada uno de estos temas.

Al lector quizás le resulte farragoso el recurso abundante a las cifras. Pero me ha parecido que este trabajo, que ofrece datos que pueden parecer llamativos y en ocasiones un tanto críticos con la realidad política de España, debía ser una presentación de hechos relevantes sobre los que cada uno pudiera obtener sus propias conclusiones, más que una interpretación subjetiva fundada más o menos correctamente en unos datos que el lector debiera buscar en unas publicaciones citadas a pie de página. 


\section{EL PÚBLICO OPINANTE}

Es quizás de más interés describir al hombre que opina en las encuestas que reflejar sus conocimientos, valoraciones y actitudes hacia los distintos aspectos de la realidad política. Situarse en esta perspectiva es, de alguna manera, volver sobre los rasgos más permanentes del español a la vez que tener la oportunidad de ver cómo las formas de vida generadas al amparo de la Constitución han moldeado las maneras de entender el mundo por parte de los españoles. Esta aproximación, por fuerza limitada, no puede alcanzar a todas las dimensiones de la persona. Se hace necesario limitarse, aunque no sea de mi gusto, a aquéIlas que están más relacionadas con la vida política. Un aproximación a lo que EASTON Ilama miembro del sistema político que no es más que el producto de abstraer de la totalidad de las acciones de un sujeto los aspectos políticos del comportamiento, ignorando así la realidad del hombre entero ${ }^{2}$. En otro lugar he manifestado mi disconformidad con este tipo de análisis sistémico que, a fuerza de ganar en pureza metodológica, pierde el sentido de totalidad, que es el único que puede darnos la clave de la conducta humana ${ }^{3}$. Aquí me referiré a algunas características de lo que podríamos llamar compromiso social y político de los españoles y que pueden dar idea de la consistencia de sus opiniones, juicios y actitudes políticas expresadas en las encuestas. No obstante, haré alguna referencia a otros aspectos que pueden ayudar a tener una visión más amplia de lo que he llamado el público opinante.

Hay un dato que llama poderosamente la atención: la orientación preferente hacia los valores que podríamos denominar privados. La salud, la familia, el trabajo, los amigos, o el bienestar económico $-y$ por este orden - son las cosas que tienen más importancia para su propia vida. La política queda postergada en el campo de los intereses de los encuestados 4 .Y este retraimiento se manifiesta después en un escasísimo nivel asociativo, tanto en sus manifestaciones más directa-

2 Cfr. EAston, D., Esquema para un análisis de la política, Amorrortu, Buenos Aires, 1969, pág. 89.

3 Cfr. Muñoz ARnaU, J. A., La educación política como función de gobierno en el Estado, Eunsa, Pamplona, 1982, págs. 259-262.

4 Estudio CIS: 2.443. Religión y sociedad. Ámbito: Toda España incluyendo las provincias insulares y excluyendo Ceuta y Melilla. Universo: Población española de ambos sexos de 18 años y más. Tamaño de la muestra: 2.487 entrevistas. Error muestral: Error teórico \pm 2 para datos globales, intervalo de confianza del $95,5 \%$ (dos sigmas); para $P=0$, en el supuesto de muestreo aleatorio simple. Fecha de realización: Del 19 al 25 de enero de 2002. 
mente políticas - partidos y sindicatos-como en el resto de los campos de la vida social. Una afiliación a los partidos del $3 \%$ o del $6 \%$ a los sindicatos - porcentaje que no sube más del $8 \%$ para el resto de las asociaciones - son cifras realmente bajas que ponen de manifiesto el individualismo de los españoles ${ }^{5}$, y aunque la situación había mejorado en el año 2000 en términos generales, en el ámbito sindical el porcentaje sólo había subido dos puntos y sólo uno en relación con la vinculación a partidos políticos ${ }^{6}$.

Por otra parte, es significativo que casi el $70 \%$ de los encuestados considere que la gente corriente no tiene ninguna influencia en lo que hace el gobierno. Por eso quizás, el interés por la política es muy bajo -el $58 \%$ de los encuestados dice interesarle poco o nada la política en 19967 , porcentaje que sube hasta el $71 \%$ en el año 2000 al preguntarse sobre la política nacional- ${ }^{8}$. El interés por la política decrece de manera considerable.

Este bajo interés se manifiesta también en que las cuestiones políticas no son tema de conversación más o menos habitual. Así, en torno al $55 \%$ rara vez, nunca o casi nunca habla con la familia, amigos o compañeros de trabajo de estos temas ${ }^{9}$.

Pero no se trata únicamente de que la política no sea tema de conversación habitual. No es que no se hable; es que tampoco se actúa. El español, por lo que se puede deducir de la lectura de las encuestas, tampoco es dado a participar a través de las vías por las que se hace presente una democracia cotidiana. A través de las formas habituales de dirigir demandas a los gobernantes para decirlo con términos eastonianos ${ }^{10}$.

5 Estudio CIS: 2206. Ámbito: nacional. Universo: Población española, ambos sexos, 18 y más años. Tamaño de la muestra: 2.494. Aspectos metodológicos: Entrevista personal. Fecha: Enero, 1996. Publicación: Datos de opinión CIS N. ${ }^{\circ} 4$; REIS n. ${ }^{\circ} 79$, págs. 267-295.

6 Estudio CIS: 2.387. Cultura política. Barómetro de marzo. Ámbito: Toda España incluyendo las provincias insulares y excluyendo Ceuta y Melilla. Universo: Población española de ambos sexos de 18 años y más. Tamaño de la muestra: 2.484 entrevistas. Error muestral: Error teórico \pm 2 para datos globales, intervalo de confianza del $95,5 \%$ (dos sigmas); para $\mathrm{P}=\mathrm{Q}$, en el supuesto de muestreo aleatorio simple. Fecha de realización: Del 24 al 28 de marzo de 2000.

Estudio CIS: 2.443. Religión y sociedad, citado.

7 Estudio C/S 2.206, citado.

8 Estudio CIS 2.387. Cultura política. Barómetro de marzo, citado.

9 Estudio CIS 2.387. Cultura política, citado.

10 Cfr. EASTON, D., Esquema para un análisis de la política, Amorrortu, Buenos Aires, 1969, pág. 166, entre otras. 
Cuando se les pregunta si: a) han asistido a una manifestación autorizada; b) firmado una petición; c) participado en una huelga; d) asistido a un mitin o reunión de algún partido o candidato; e) escrito cartas a las autoridades locales, autonómicas o nacionales para denunciar un problemas; f) o a los medios de comunicación; g) dedicado parte de su tiempo a trabajar por un partido o un candidato; h) o contribuido económicamente al sostenimiento de un partido político o la campaña de un candidato, las respuestas demuestran desinterés - contestan que no lo han hecho ni lo harían en ningún caso un $33 \%$ para a); un $28 \%$ para b); un $35 \%$ para c); un $49 \%$ para d); un $38 \%$ para e); un $38 \%$ para f); un $74 \%$ para g); y un $78 \%$ para $h$ ) - y una cierta apatía o desinterés cualidades que nuestros clásicos testimonian como un rasgo definitorio de los españoles 11 . En efecto, a la pregunta de no lo ha hecho, pero estaría dispuesto a hacerlo, las respuestas son: un $29 \%$ para a); un $37 \%$ para b); un $33 \%$ para c); un $23 \%$ para d); un $51 \%$ para e); un $52 \%$ para f); un $19 \%$ para g); y un $16 \%$ para h). El desencanto producido por haber realizado alguna de las acciones citadas sin obtener satisfacción, traducido en las respuesta lo ha hecho,pero no lo haría otra vez oscila entre un $2 \%$ para e), f), g) y h) y un $6 \%$ para d). Obtiene un $5 \%$ a) y c) y un $4 \%$ b) ${ }^{12}$. Es de notar la escasa utilización de los medios de comunicación como instrumentos para la denuncia de los problemas existentes. Definitivamente el régimen español no es un régimen de opinión pública.

En todo caso estos datos significan que la nuestra es una democracia intermitente desde el punto de vista de los ciudadanos, en la medida en que las manifestaciones democráticas se reducen en buena parte a la participación electoral.

Si se quiere saber dónde se sitúan los españoles en la escala izquierda-derecha en la que 1 indicaría izquierda y diez derecha sólo un $7 \%$ se sitúa en la izquierda $-1-2$ en la escala - y un $2 \%$ en la derecha -9-10 en la escala-, un 33,2\% se sitúa en los puntos 5-6 de la escala y un $29,1 \%$ en las posiciones 3-4. La respuesta no sabe o no contesta supone un porcentaje del $18,9 \%$. Esto quiere decir que la población española mayoritariamente se siente de izquierda moderada al menos en el momento de realizarse la encuesta - abril de $2003-{ }^{13}$. En unas

1 Cfr. MEnÉndez PIDAL, R., "Los españoles en la Historia", España y su historia, citado por FrANCO, D., España como preocupación, Argos Vergara, Barcelona.

12 Estudio CIS 2.387. Cultura política, citado.

13 Estudio n. 2.50 8. Abril 2003. Ámbito: Nacional. Universo: Población española de ambos sexos de 18 años y más. Tamaño de la muestra: Diseñada: 
encuestas aplicadas a los jóvenes en $1997^{14}$ los resultados eran parejos: en una escala de 1 a 10 en que 1 era izquierda y 10 derecha, la media se situaba en 4,6 .

Este es el perfil político del español que opina en la encuestas, con todas las reservas que puedan hacerse a los procedimientos demoscópicos y a la selección e interpretación que yo he hecho de los datos a los que he tenido acceso.

El perfil político puede completarse con estos rasgos de carácter que los españoles se atribuyen; los españoles se sienten, por este orden, buena gente, alegres, abiertos, trabajadores, amantes de su tierra, amables y hospitalarios pero poco prácticos y responsables ${ }^{15}$.

El español, que se da cuenta con claridad de lo mucho que han cambiado las cosas en los últimos tiempos $-y$ en general opinan que

2.500 entrevistas. Realizada: 2.494 entrevistas. Afijación: Proporcional. Ponderación: No procede. Puntos de muestreo: 168 municipios y 47 provincias. Procedimiento de muestreo: Polietápico, estratificado por conglomerados, con selección de las unidades primarias de muestreo (municipios) y de las unidades secundarias (secciones) de forma aleatoria proporcional, y de las unidades últimas (individuos) por rutas aleatorias y cuotas de sexo y edad. Los estratos se han formado por el cruce de las 17 comunidades autónomas con el tamaño de hábitat, dividido en 7 categorías: menor o igual a 2.000 habitantes; de 2.001 a 10.000 ; de 10.001 a 50.000; de 50.001 a 100.000; de 100.001 a 400.000; de 400.001 a 1.000.000, y más de 1.000 .000 de habitantes Los cuestionarios se han aplicado mediante entrevista personal en los domicilios Error muestral: Para un nivel de confianza del $95,5 \%$ (dos sigmas), y $\mathrm{P}=\mathrm{Q}$, el error real es de $\pm 2,0 \%$ para el conjunto de la muestra y en el supuesto de muestreo aleatorio simple. Fecha de realización: Del 24 al 30 de abril de 2003. Estos datos hay que tomarlos con cautela dado el momento de aplicación de la encuesta, después de una intensa campaña de agitación social motivada por la guerra de Irak.

14 Los jóvenes de hoy Estudio CIS 2.257. Juventud e identidad nacional Ámbito: Toda España incluyendo las provincias insulares y excluyendo Ceuta y Melilla. Universo: Población española de ambos sexos entre 15 y 29 años. Tamaño de la muestra: 2.437 entrevistas. Error muestral: Error teórico \pm 2 para datos globales, intervalo de confianza del $95,5 \%$ (dos sigmas); para $\mathrm{P}=\mathrm{O}$, en el supuesto de muestreo aleatorio simple. Fecha de realización: Del 11 al 21 de septiembre de 1997.

15 Estereotipos regionales. Estudio CIS número 2.123. Ámbito: Toda España incluyendo las provincias insulares y excluyendo Ceuta y Melilla. Universo: Población española de ambos sexos de 18 años y más que vive en municipios de más de dos mil habitantes. Tamaño de la muestra: 3.004 entrevistas. Error muestral: Error teórico $\pm 1,91$ para datos globales, intervalo de confianza del $95,5 \%$ (dos sigmas); distribución de la varianza del 50/50\%. Fecha de realización: 17 de noviembre-12 de diciembre de 1994. 
para bien $-{ }^{16}$ piensa, no obstante, en un $88 \%$, que «a pesar de todo lo que ha cambiado la vida, todavía existen unas reglas básicas por las que guiarse» y que "a la larga, en la vida lo mejor es ser honrado (91\%)". Es capaz de sentir la llamada de la generosidad - la solidaridad, que es un valor constitucional: "me doy cuenta de que puedo ayudar a los demás de muchas maneras» $(89 \%)$ - y está predispuesto a la amistad - "uno siempre puede encontrar amigos si lo intenta» $(87 \%)-17$.

Cuando se les pregunta a los españoles si una serie de palabras les despierta simpatía o adhesión, o bien rechazo u oposición por lo que para ellos representan, la que ocupa el lugar más alto en el aprecio es la igualdad (93\%) seguida de tolerancia (89\%), democracia $(84 \%)^{18}$, orden $(83 \%)$, pacifismo $(81 \%)$, ecologismo $(79 \%)$, disciplina $(73 \%)$, tradición (72\%). Llama la atención este equilibrio de valores y sobre algunos es bueno hacer alguna consideración. En primer lugar sobre la igualdad. A mi modo de ver esta igualdad que despierta sim-

16 Al preguntar si la forma de ser y de pensar de la gente tenía muy poco que ver con el pasado un $64 \%$ opinaba que si, un $22 \%$ que no y un 145 no sabia o no contestaba. Cfr. Estudio CIS 2.201, diciembre 1995. Transición y democracia. Ámbito: Toda España incluyendo las provincias insulares y excluyendo Ceuta y Melilla. Universo: Población española de ambos sexos de 18 años y más. Tamaño de la muestra: 2.478 entrevistas. Error muestral: Error teórico \pm 2 para datos globales, intervalo de confianza del $95,5 \%$ (dos sigmas); distribución de la varianza del $50 / 50 \%$. Fecha de realización: $9-14$ de diciembre de 1995 . Al repetir la pregunta en 1997 el 39\% opinaba que había cambiado mucho, bastante el $44 \%$, poco un $10 \%$, nada el $3 \%$ y no sabe o no contesta el $4 \%$. El $21 \%$ opinaba que los cambios habían sido muy positivos, el $61 \%$ bastantes positivos, el $10 \%$ poco positivos el $4 \%$ negativos y no sabía o no contestaba el $4 \%$. Cfr. Barómetro de junio. Estudio CIS 2.252, junio 1997. Ámbito: Toda España incluyendo las provincias insulares y excluyendo Ceuta y Melilla. Universo: Población española de ambos sexos de 18 años y más. Tamaño de la muestra: 2.500 entrevistas. Error muestral: Para un nivel de confianza del $95,5 \%$ (dos sigmas) y $P=Q$, el error es de \pm 2 para el conjunto de la muestra. Fecha de realización: 20-24 de junio de 1997.

17 Tolerancia y aceptación social. Estudio CIS 2.212, abril 1996, Boletín n. ${ }^{\circ}$ 5. Ámbito: Toda España incluyendo las provincias insulares y excluyendo Ceuta y Melilla. Universo: Población española de ambos sexos de 18 años y más. Tamaño de la muestra: 2.499 entrevistas. Error muestral: Error teórico \pm 2 para datos globales, intervalo de confianza del $95,5 \%$ (dos sigmas); para $\mathrm{P}=\mathrm{Q}$. Fecha de realización: 13-17 de abril de 1996.

18 Cuando en 1979, el Barómetro de septiembre, REIS n. ${ }^{\circ}$, se preguntaba a los españoles si con la democracia actual -la de entonces - los problemas del país se iban a solucionar, iban a quedar igual o ir cada vez peor, los encuestados creían lo primero en un $34 \%$, lo segundo un $27 \%$ y lo tercero un $21 \%$. No sabia o no contestaba el 19\%. Esos porcentajes mejoraban en los sucesivos Barómetros. 
patías no tiene que ver en absoluto con una presunta difusión de valores de índole socializante; con una nivelación progresiva en los medios de fortuna. No es un resultado de la capacidad informadora de la igualdad que se enuncia como valor en el art. 1 de la Constitución. Es algo que precede a la Constitución. Tiene que ver con la honra: la conciencia de la radical igualdad en la dignidad. Al menos como honra viene documentada por los escritores del Siglo de Oro. "Soy - decía un castellano al ser preguntado en el siglo XVII - tan hidalgo como el Rey, $Y$ aún más, porque él es medio flamenco" ${ }^{19}$. Lo que afirmo tiene su fundamento en que entre las palabras que se presentaban a la valoración estaba también socialismo, que despierta más bien simpatía a un $45 \%$, más bien rechazo a un $13 \%$ e indiferencia a un $35 \%$-obsérvese la distancia con respecto a la igualdad- detrás por cierto de la palabra ejército. Peor suerte le corría a la palabra comunismo que provoca la simpatía de un $18 \%$ el rechazo del $27 \%$ y la indiferencia del $47 \%$, al lado de un $8 \%$ que no sabe o no contesta. Por otra parte, a pesar de estar en una sociedad de bienestar en la que los bienes materiales se tienen en gran aprecio y ser la envidia un pecado capital español, según algunos, el español se confiesa uen general [...] satisfecho con lo que me ha deparado la vida" ( $77 \%$ ) frente a un $18 \%$ que no lo está y un $6 \%$ que no sabe o no contesta. ¿Será un reflejo aunque atenuado de aquella sobriedad que despertaba la admiración del galoTrogo Pompeyo?20, - ¿tendrá que ver con lo que Azorín reflejaba en Los Pueblos - Un hidalgo - cuando decía: "Ésta es la grandeza española: la simplicidad, la fortaleza, el sufrimiento largo y silencioso bajo serenas apariencias; esta es una de las raices de la patria que ya se van secandon? ${ }^{21}$

No es menos de señalar el valor parejo de democracia y orden. El español no los ve como opuestos, sino como complementarios y próximos. ¿Y qué decir de la tradición? Despierta simpatías al $72 \%$ y sólo provoca el rechazo del $7 \%$ y la indiferencia del $14 \%$ - el $6 \%$ no sabe o no contesta- ${ }^{22}$. Tradición y democracia no son incompatibles.

19 Cfr. MEnéndez PidAL, R., "Los españoles en la Historia", España y su historia, citado por Franco, D., España como preocupación, Argos Vergara, Barcelona, pág. 358.

20 Cfr. Menéndez Pidal, R., "Los españoles...", op. cit., pág. 351.

21 Cfr. Azorín, Obras Completas, tomo I, Ed. de Ángel Cruz Rueda, Aguilar, Madrid, 1975, pág. 718.

22 Me parecen acertadísimas las reflexiones de Menéndez Pidal sobre el significado de tradición y tradicionalismo y su diferencia con lo que llama misoneísmo. Cfr. MENÉndez PIDAL, R., "Los españoles...", op. cit., págs. 359-360. 
Tengo para mí que a veces los políticos no leen las encuestas y si las leen parece que se gozan en ir contra lo que piensan los ciudadanos. $Y$ de ahí surge el desinterés por la política.

Aunque el español haya cambiado en cuanto a sus comportamientos religiosos, en el año 2002, al preguntársele cómo se define en materia religiosa: católico, creyente de otra religión, no creyente o ateo, un $80 \%$ se consideraba católico y un $1 \%$ creyente de otra religión. Sólo un $12 \%$ se manifestaba como no creyente. Un $79 \%$ decía que si tuviera que tener un hijo lo bautizaría y un $7 \%$ dudaba. Me parece que estos datos son relevantes y los poderes públicos no deberían desconocerlos. No es tarea del Estado una empresa que consista en minar los principios de índole religiosa y moral compartidos por una mayoría tan amplia de la población ${ }^{23}$.

Queda por ver, para acabar este apartado, cuál es la identificación del español con su nación. A la altura de enero de 1989 se preguntaba a los españoles excepto a los de Cataluña y País Vasco si se consideraban más españoles que de su región, más de su región que español o ambas cosas por igual. Un $25 \%$ se confesaba más español, un $18 \%$ más de su región y ambas cosas por igual el $52 \%$. No sabía o no contestaba un 4\%. En Cataluña y el País Vasco las posibilidades de respuesta se ampliaban. Si los que se sentían únicamente españoles o más españoles que catalanes o vascos suponian un porcentaje del $23 \%$ - muy próximo al $25 \%$ que declaran el resto de los españoles-, el porcentaje de los que se sienten igualmente españoles que vascos o catalanes bajaba al $33 \%$; un $24 \%$ se sentía menos español que catalán o vasco - seis puntos más que en el caso anterior-y un $15 \%$ que no se sentia español: sólo vasco o catalán ${ }^{24}$.

El resultado no sorprende en ambos casos. Habría que ver la decisión que tomaría ese $15 \%$ si se viera en la disyuntiva de tener que elegir entre una de las dos posibilidades. O cuál sería la respuesta ante una coyuntura crítica que pusiera de manifiesto los verdaderos sentimientos nacionales. En todo caso, el sentimiento nacional rectamente entendido hay que cultivarlo $-y$ mantenerlo en sus justos términos- a través de la educación.

23 Estudio CIS 2.443. Religión y sociedad, citado.

24 Cultura Política (II), $\mathrm{n}^{\circ}$ estudio: 1.788. Fecha: enero, 1989. Tamaño: 3.356. Universo: Población española, ambos sexos, 18 y más años. Ámbito: nacional. Aspectos metodológicos: Entrevista personal. Publicación: REIS n. ${ }^{\circ} 49$, págs. 311-387. 


\section{EL SISTEMA EDUCATIVOY LOS MEDIOS DE COMUNICACIÓN EN LA FORMACIÓN DE LA CULTURA POLÍTICA}

Sólo un breve apunte sobre el sistema educativo y los medios de comunicación en tanto que son dos instrumentos institucionales a través de los cuales se transmiten en cualquier sistema social conocimientos y valoraciones hacia el sistema político y se suscitan actitudes que acaban por traducirse en comportamientos políticos determinados. Aunque aquéllos pueden transmitirse por ósmosis, no cabe duda que tanto el sistema educativo como la opinión pública libre, creada sobre todo por los medios de comunicación ${ }^{25}$, están llamados a jugar un papel determinante en la configuración de una sociedad libre, estructurada conforme a la idea de lo que significa un Estado social y democrático de Derecho. Me limitaré a señalar que cuando se pregunta a los españoles sobre el grado de confianza que le inspiran distintas instituciones, la escuela y el sistema educativo resultan ser las que ocupan el primer lugar. Esto debería hacer pensar a los gobernantes sobre las posibilidades de la institución de cara a la educación política de los ciudadanos y la importancia de los debates públicos sobre determinados contenidos educativos. La idea de patriotismo constitucional o la cuestión de las humanidades no son asuntos menores de los que quepa hacer un uso coyuntural para malbaratarlos e ignorarlos después, puesto que en el fondo late el problema de la realidad histórica de España en la que la Constitución se funda; el papel de las distintas comunidades históricas, la formación en unos valores explícitos o implícitos en el texto constitucional ${ }^{26}$.

La orientación de las personas hacia las realidades políticas se forja también a partir de la reflexión más o menos elaborada sobre la información que los medios de comunicación proporcionan y por el intercambio de opiniones sobre temas políticos entre las personas del entorno vital de cada uno.

Sobre el papel que juegan los medios de comunicación en la creación de esa opinión pública ${ }^{27}$, las encuestas nos dicen que la TV

25 No hace falta insistir demasiado en la importancia que el TC y el TEDH conceden a la opinión pública libre en orden a salvaguardar una sociedad democrática. Vid. por todas la STC 20/1990, de 15 de febrero, FJ.4, y la STEDH Castells c. España.

26 Estudio CIS 2.443. Religión y sociedad, citado.

27 Estudio CIS 2.396. Barómetro de julio. Los españoles y los medios de comunicación. Ámbito: Toda España incluyendo las provincias insulares y exclu- 
es el medio informativo más utilizado. El $79 \%$ de los encuestados veía la TV todos los días o casi todos los días y, de los que veían la TV con mayor o menor frecuencia, un $67 \%$ veia los telediarios y otros programas informativos habitualmente; al $72 \%$ de los que veían laTV con mayor o menor frecuencia les merecía mucha o bastante confianza las noticias que daban las distintas cadenas. La radio la seguía a distancia considerable $(46 \%$ de los entrevistados la escuchaban todos o casi todos los días y un $48 \%$ escuchaba habitualmente noticias o informativos y estas informaciones les ofrecian mucha o bastante confianza al $78 \%$ ). Sólo un $26 \%$ leía la prensa todos o casi todos los días y de los que leían con mayor o menor frecuencia, el 93\% utilizaba la de información general.

El elevado número de horas que buena parte de los españoles dedican a ver programas deTV de distinta naturaleza indica que se ven sometidos a un tipo de influencias muy variado, sin advertir que puede tener una considerable carga política encubierta.

No obstante los niveles de confianza en la información ofrecida por los medios, más de la mitad de lo encuestados confesaban tener poca o ninguna confianza en los medios de comunicación ${ }^{28}$.

\section{CONOCIMIENTOS, VALORACIONESY ACTITUDES DE LOS ESPAÑOLES}

¿Cuál es la orientación hacia las realidades políticas de ese español que opina en la encuestas? Resulta claro que la respuesta que puede darse aquí es incompleta por las limitaciones objetivas - la brevedad- de este trabajo. De todas formas, tal como adelantaba anteriormente, me parece que las respuestas más relevantes para este estudio son las que se refieren a las cuestiones que paso a considerar.

\section{El Régimen político anterior}

En la medida que el régimen que instaura la $C E$ se basa en unos principios de legitimidad distintos a los que sustentaban la España de

yendo Ceuta y Melilla. Universo: Población española de ambos sexos de 18 años y más. Tamaño de la muestra: 2.493 entrevistas. Error muestral: Error teórico \pm 2 para datos globales, intervalo de confianza del $95,5 \%$ (dos sigmas); para $P=0$, en el supuesto de muestreo aleatorio simple. Fecha de realización: Del 13 al 18 de julio de 2000.

28 Estudio C/S 2.443, citado. 
Franco y que aquel régimen tuvo el origen de todos conocido, me parece de interés reflejar cuál es-con la perspectiva que da el tiempo- la valoración de los españoles sobre el pasado inmediato. Preguntados a la altura de $1995^{29}$ sobre cómo pasaría a la historia el régimen de Franco, un $11 \%$ opinaba que como un periodo positivo para España, el $34 \%$ como un periodo negativo y un $49 \%$ como una etapa que tuvo cosas buenas y malas. Estos porcentajes variaban según las categorías de edad, por ejemplo en la comprendida entre los 55/64 años los porcentajes eran del $16 \%, 27 \%$ y $51 \%$, respectivamente. $Y$ al preguntarles acerca de cómo pasaría a la historia la figura de Franco, un $88 \%$ contestaba que como un dictador -entre las alternativas de respuesta que se les ofrecían - y un $26 \%$ opinaba que como uno de los mejores gobernantes que ha tenido España, mientras un $59 \%$ opinaba que no y un $15 \%$ no sabía o no contestaba. Se puede afirmar que las respuestas tienen un tono maduro, ajeno a cualquier radicalismo.

En lo que se refería a los orígenes del régimen político anterior, el $48 \%$ de los españoles pensaba - frente a un $42 \%$ - que se habían olvidado las divisiones y rencores que en el pasado creó la guerra civil.

\section{La transición política}

La imagen que los españoles tienen de la transición es positiva hasta el punto de que un $79 \%$ la considera un motivo de orgullo, frente al $9 \%$ que opina lo contrario. Los españoles no se equivocaron en su opción por el cambio político y esa opinión se mantiene en el tiempo, sin que el porcentaje de los satisfechos decaiga. Además es consciente de su propio protagonismo en ese proceso que sólo cede ante el papel del Rey. En efecto, el Rey y los ciudadanos en general, seguidos de los partidos políticos, fueron - en su opinión- los que más contribuyeron al éxito de la transición. Estos datos - valoración positiva de la transición y conciencia del protagonismo del pueblo en dicho proceso- son, a mi parecer, de los más positivos que cabe deducir de la lectura de las encuestas ${ }^{30}$. Es llamativo que la consideración positiva del papel de los partidos en la transición evolucione tan negativamente con el paso del tiempo hasta el punto de ser una de las instituciones peor valoradas, como tendremos ocasión de comprobar.

29 Estudio CIS 2.201, diciembre 1995. Transición y democracia, citado.

30 Estudio CIS 2.201, diciembre 1995. Transición y democracia, citado. 


\section{El Estado, la democracia y la participación política}

Creo que puede resultar de interés, aun sin tener en cuenta el estado anterior de la cuestión ni su posible evolución, lo que opinaban los españoles sobre lo que deberian constituir o no responsabilidades del Estado. Es decir, las respuestas sobre cuál debe ser el «tamaño" del Estado social - si se me permite hablar así-. En enero de 1996, al preguntar el CIS sobre si deberían constituir o no responsabilidades del Estado: a)el ofrecer asistencia sanitaria para todos; b) asegurar pensiones dignas a los ancianos; c) ofrecer becas a los estudiantes universitarios procedentes de familias de pocos ingresos; d) facilitar una vivienda digna a las familias con pocos ingresos; e)imponer regulaciones estrictas para que la industria cause menos daño al medio ambiente; f) prestar a la industria el apoyo que necesita para su desarrollo; g) crear un puesto de trabajo para todo aquel que lo demanda; $y$ h) asegurar un subsidio digno para los parados, las repuestas sí, sin ninguna duda y probablemente debería, del $98 \%, 98 \%, 97 \%$, $96 \%, 93 \%, 92 \%, 89 \%$ y $90 \%$, según el orden que he establecido. Sin embargo cuando se les pregunta sobre qué debería hacer el gobierno: gastar más en servicios públicos y prestaciones sociales o bajar los impuestos sólo el $43 \%$ está a favor de mayor gasto aunque signifique pagar más impuestos; un 33\% prefiere la rebaja de impuestos aunque disminuyan las prestaciones y un $24 \%$ no sabe o no contesta. Los ciudadanos no parecen ser conscientes de que las prestaciones del Estado no son - en el mejor de los casos - más que una "devolución" más o menos equitativa y redistribuidora de lo que previamente le han entregado $^{31}$.

Puede resultar también conveniente preguntarse sobre el nivel de satisfacción ciudadana por el funcionamiento de los servicios públicos, que es lo mismo que preguntarse sobre la eficacia del Estado social. El porcentaje de españoles que decía sentirse muy satisfecho o bastante satisfecho en septiembre de 1992 con el funcionamiento de la enseñanza era del $54 \%$ y $59 \%$ en abril de 1996; la asistencia sanitaria en los hospitales de $35 \%$ y $52 \%$ respectivamente; asistencia sanitaria en ambulatorios $33 \%$ y $52 \%$; correos $36 \%$ y $67 \%$; teléfonos $48 \%$

31 Los ciudadanos y el Estado. Estudio CIS 2.206, enero 1996. Ámbito: Toda España incluyendo las provincias insulares y excluyendo Ceuta y Melilla. Universo: Población española de ambos sexos de 18 años y más. 2.494 entrevistas. Error muestral: Error teórico \pm 2 para datos globales, intervalo de confianza del 95,5\% (dos sigmas); para $P=Q$. Fecha de realización: 27-31 de enero de 1996. 
y $77 \%$; gestión de las pensiones $37 \%$ y $47 \%$; policía $44 \%$ y $60 \%$; administración de justicia $23 \%$ y $29 \%$; servicios sociales $34 \%$ y $50 \%$; protección por desempleo $26 \%$ y $33 \%$; oficinas de la administración pública $29 \%$ y $33 \%$; ferrocarriles $40 \%$ y $58 \%$; transporte aéreo $43 \%$ y $53 \%$; transporte urbano 47 y $65 \% 32$. Como puede verse, existe un aumento del nivel de satisfacción en todos los casos $y$, en algunos, significativos, pero en términos absolutos los porcentajes son más bien pobres, y en algunos casos me atrevería a calificar de alarmantes.

En una encuesta aplicada entre los días 14-21 de junio del $78^{33}$ sólo un $16 \%$ de los españoles opinaba que las leyes se aplicaban por lo general a todos por igual. Menéndez Pidal hablaba, para referirse a la total trayectoria histórica de España, de «...un común irrespeto a la ley, sea por juzgarla poco equitativa para el caso dado, sea por indeliberado desprecio hacia el interés colectivo. "Las leyes, se dice, sólo sirven para darse el gusto de no cumplirlas"; abyecto placer, gustado sobre todo por los gobernantes mismos en las decadencias.... ${ }^{34}$. En diciembre de 1990 , el $34 \%$ de los españoles opinaba que la Constitución se respetaba poco o nada ${ }^{35}$ y en 1996 sólo el $62 \%$ de lo españoles pensaba que las leyes debían cumplirse siempre, frente al $35 \%$ que opinaba que en ocasiones había que actuar según la propia conciencia - un $4 \%$ no sabía- ${ }^{36}$.

Al referirme al perfil del español que opina en las encuestas aludí al déficit en cuanto a la diversidad de formas de participación política en estos años. Sin embargo, como también he señalado, la palabra democracia es una de las que despiertan más simpatía entre los españoles. Y aquí nos encontramos con otra de las conclusiones más positivas que puedan sacarse de la lectura de las encuestas. En 1985 la democracia era preferible a cualquier otro sistema de gobierno para el $69 \%$ de los españoles, porcentaje que subía en 1988 al $72 \%$, al $73 \%$ en $1992^{37}$ y al $79 \%$ en 1995 . mientras que un $9 \%$ prefería - en ese añoun régimen autoritario, y un $8 \%$ era indiferente - un $4 \%$ no sabía o no contestaba $-{ }^{38}$. En el año 2000 , los que preferían la democracia a cual1996.

Boletín del Centro de investigaciones Sociológicas, $n .^{\circ} 5$,.junio de 1996. «Informe sobre la encuesta de victimización» REIS, $\mathrm{n} .^{\circ} 2$.

Cfr. MENÉNDEZ PIDAL, R., "Los españoles...", op. cit., pág. 366.

REIS $n .^{\circ} 56$.

Los ciudadanos y el Estado. Estudio CIS 2.206.

37 Boletín del Centro de investigaciones Sociológicas, $n .{ }^{\circ} 3$, febrero de

Estudio CIS 2.201, diciembre 1995. Transición y democracia, citado. 
quier otra forma de gobierno subían hasta el $86 \%$; un $4 \%$ pensaba que algunas circunstancias un régimen autoritario podía ser preferible a uno democrático y se mantenía el porcentaje de indiferentes - un $3 \%$ no sabía o no contestaba- ${ }^{39}$. La democracia - 1989- se identifica en primer lugar con las libertades, después con la participación, la igualdad y la justicia social40.

Esta alta valoración de la democracia como forma política en abstracto quedaba matizada cuando se preguntaba sobre el grado de satisfacción sobre su funcionamiento en España. Se consideraban muy satisfechos sólo el $7 \%$, bastante satisfechos un $57 \%$, poco satisfecho un $27 \%$, nada satisfecho un $6 \%$ y no sabia o no contestaba un $4 \%$.La suma de los poco o nada satisfechos es un porcentaje relativamente elevado, que indica que hay cosas que deben ser corregidas si se quiere que la democracia siga recibiendo un apoyo mayoritario ${ }^{41}$.

Completaré lo que antes he dicho sobre la participación refiriéndome específicamente a la electoral. Preguntados los españoles después de las elecciones de marzo de 1993, confesaban votar siempre o casi siempre el $87 \%$, no votar nunca o casi nunca un $6 \%$ y votar sólo algunas veces un $7 \%{ }^{42}$. En mi opinión estas cifras suponen un nivel aceptable de participación.

\section{La Constitución}

Es de señalar la percepción que los españoles tienen de la Constitución como un producto del consenso y en todo caso de su carácter ideológicamente equilibrado. Preguntados en 1995 sobre qué intereses o ideas prevalecieron en la Constitución al redactarse, un 52\%

39 Estudio CIS 2.387, marzo 2000. Cultura política, citado.

40 Cfr. REIS $n .^{\circ} 49$, enero-marzo de 1990.

41 Estudio CIS 2.387, marzo 2000. Cultura política, citado.

42 Estudio CIS 2.210. Ámbito: Toda España incluyendo las provincias insulares y excluyendo Ceuta y Melilla Universo: Población española de ambos sexos de 18 años y más. Tamaño de la muestra: 5.350 entrevistas. Error muestral: Error teórico $\pm 1,41$ para datos globales, intervalo de confianza del $95,5 \%$ (dos sigmas); para $P=0$. Fecha de realización: 16-24 de marzo de 1996. Estudio CIS 2.215. Ámbito: Toda España incluyendo las provincias insulares y excluyendo Ceuta y Melilla. Universo: Población española de ambos sexos de 18 años y más. Tamaño de la muestra: 2.496 entrevistas. Error muestral: Error teórico \pm 2 para datos globales, intervalo de confianza del $95,5 \%$ (dos sigmas); para $P=0$. Fecha de realización: 29 de mayo-2 de junio de 1996. 
contesta que todos y ninguno, el $10 \%$ que las ideas de centro, un $7 \%$ las de la derecha, un $6 \%$ las de izquierda y no sabian o no contestaba el $25 \% 43$. Esta percepción era intuición o producto de la reiteración de afirmaciones de ese tipo hechas por los políticos o los medios de comunicación puesto que, como se verá más abajo, la Constitución es poco conocida "intelectualmente". Son ideas adquiridas por ósmosis, que han ido calando con el tiempo en la sociedad española. La Constitución es "conocida" por sus efectos, es un conocimiento "material" el que se tiene, centrado en las líneas esenciales.

A la altura de 1988 los españoles que estaban muy o bastante satisfechos con la Constitución eran un $56 \%$. El porcentaje bajó hasta el $51 \%$ en 1992 y volvió a subir hasta el $64 \%$ en 1995 . Los poco o nada satisfechos eran, tanto en 1988 como en 1992, un 30\%, porcentaje que bajó hasta el $25 \%$ en 1995. Los que no sabian o no contestaban pasaron del $14 \%$ al $19 \%$ y en el 1995 al $11 \%$. El año 1992 fue un año negativo: descendió el número de satisfechos y creció el número de los que no sabían o no quisieron contestar ${ }^{44}$.

Al cumplirse los 20 años de la Constitución, la posición de los españoles ante ella quedaba reflejada en la encuesta correspondiente al Barómetro de noviembre. Cuando se preguntaba por el grado de satisfacción - a) muy satisfecho; b) bastante; c) poco o d) nada satisfecho- con la CE, los porcentajes eran del $7 \%, 61 \%, 19,3 \%$, y $4 \%$, respectivamente. El $8 \%$ no sabía y no contestaba el $6 \%$. La situación había mejorado notablemente: un $4 \%$ más en la categoría de los muy y bastante satisfechos.

Al preguntarles sobre el grado de conocimiento que tenían en general los españoles sobre la $\mathrm{CE}$, sólo un 3,3\% decían que la conocemos bien, un $31,6 \%$ por encima, muy poco el $40,7 \%$, casi nada el $18,3 \%$; no sabía el $6 \%$ y no contestaba el $1 \% 45$, y sobre en qué medida la CE podía ayudar a resolver los problemas de los españoles, tenian mucha o bastante confianza el $53,2 \%$, poca o ninguna confianza el $37,2 \%$, frente al $9,6 \%$ que no sabía o no contestaba 46 .

43 Estudio CIS 2.201, diciembre 1995. Transición y democracia, citado.

44 Boletín del Centro de Investigaciones Sociológicas, n. ${ }^{\circ} 3$, febrero de 1996 , citado.

45 Estos resultados suponían una mejora en relación con los resultados de diciembre de 1990 que eran, respectivamente: $2 \%, 21 \%, 41 \%, 31 \%, 5 \%$.

46 Estudio CIS.n. ${ }^{\circ} 2311$, de noviembre. Ámbito: Nacional. Se incluyen las provincias insulares y se excluyen Ceuta y Melilla. Universo: Población española 
En relación con el conocimiento de la Constitución, a la altura de 1989 los españoles opinaban que los sucesivos gobiernos constitucionales se habían esforzado poco para que los ciudadanos conocieran la Constitución y cerca del $90 \%$ pensaba que debía ser enseñada a los niños en las escuelas y también a todos a través de la TV. La correcta enseñanza de la Constitución en la Escuela es otro de los retos que hay que afrontar ${ }^{47}$.

Cuando en círculos académicos o políticos se habla de la posible reforma de la Constitución hay una cierta coincidencia acerca de lo que debe ser reformado - aunque no haya acuerdo en el "sentido» de la reforma -, a la vez que se traduce con alguna frecuencia un vago temor a iniciar un proceso de cambio. El ciudadano lo ve de otra manera. Quizás porque desconoce el instituto de la reforma, o si se quiere, mejor, porque desconoce las posibilidades que ofrece una Constitución abierta a las distintas mayorías que pueden formarse en el Parlamento sin necesidad, por eso, de alterar la Constitución. Cuando se pregunta al ciudadano qué aspectos de la Constitución deberían reformarse, las respuestas o son vagas o se refieren, en efecto, a cuestiones que podrían cambiarse a través de la legislación. Lo que sí queda claro es que los españoles no tienen miedo a un cambio $y$ una porción considerable de la población no tiene formada opinión o no contesta. Así en 1995 el $46 \%$ de la población decía que había que reformarla, el $33 \%$ que había que dejarla como está y no sabía o no contestaba el $21 \%$.

de ambos sexos de 18 años y más. Tamaño de la muestra: Diseñada: 2.500 entrevistas. Realizada: 2.498 entrevistas. Afjjación: Proporcional. Ponderación: No procede. Puntos de Muestreo: 167 municipios y 48 provincias. Procedimiento de muestreo: Polietápico, estratificado por conglomerados, con selección de las unidades primarias de muestreo (municipios) y de las unidades secundarias (secciones) de forma aleatoria proporcional, y de las unidades últimas (individuos) por rutas aleatorias y cuotas de sexo y edad. Los estratos se han formado por el cruce de las 17 comunidades autónomas con el tamaño de hábitat, dividido en 7 categorias: menor o igual a 2.000 habitantes; de 2.001 a 10.000; de 10.001 a 50.000; de 50.001 a 100.000 ; de 100.001 a 400.000 ; de 400.001 a 1.000 .000 , y más de 1.000 .000 de habitantes. Los cuestionarios se han aplicado mediante entrevista personal en los domicilios. Error muestral: Para un nivel de confianza del 95,5\% (dos sigmas), y $\mathrm{P}=\mathrm{Q}$, el error es de $\pm 2 \%$ para el conjunto de la muestra y en el supuesto de muestreo aleatorio simple. Fecha de realización: Del 26 ał 30 de noviembre de 1998.

47 Estudio CIS n. ${ }^{\circ} 1851$, de diciembre de 1989. 


\section{Las instituciones de gobierno generales}

Conocidas las orientaciones de los españoles hacia los aspectos básicos del sistema político, conviene hacer algunas consideraciones acerca de las distintas instituciones de gobierno, empezando por las que tienen un carácter general.

\subsection{La Corona}

Dos tipos de cuestiones deben ser tenidas en cuenta en este caso: la orientación de los españoles hacia la Monarquía como "forma política del Estado" y la especial adhesión a la persona que actualmente encarna la Corona, vinculada al proceso de la transición de una manera especial, además de a la preservación del orden constitucional con el que, desde luego, se identifica la Monarquía.

En los dos casos, la institución queda bien valorada, tal como queda reflejado en el Estudio CIS n. ${ }^{\circ} 1851$ de diciembre de 1989, aunque en esas fechas el porcentaje de los que no saben o no contestan es alto en lo que se refiere a la institución en abstracto. El papel del Rey D. Juan Carlos es valorado muy positivamente, tanto en lo que se refiere al momento de la transición, como en relación con el golpe.de Estado del 23-F. Queda clara la adhesión y simpatía de los españoles como la conciencia de que la Monarquía está anclada en la tradición y la historia de España.

La Monarquía - a la altura de 1995 - es sin duda la institución que merece más confianza a los españoles: 7,5 sobre 10 , a distancia considerable del Defensor del Pueblo, que le sigue ${ }^{48}$. Esta posición la mantenía en $1998^{49}$.

\subsection{Las Cortes Generales}

Por los resultados de las encuestas, los españoles parecen percibir con claridad la dignidad de las Cortes Generales como representación del pueblo español (art. 66.1 CE) y titulares de funciones soberanas. Son - al menos lo parece - conscientes de su importancia institucional. Sin embargo, lo que hacen interesa en menor medida o

48 Estudio CIS 2201, diciembre 1995. Transición y democracia, citado.

49 Estudio CIS 2309, diciembre 1998. La democracia y sus instituciones. 
es valorado menos positivamente o se considera que incide menos en su vida. Y uno tiene la impresión de que parecen quedar un tanto lejanas de los ciudadanos. Aquella visión de Hauriou expresada hace ya tanto tiempo sobre el Poder Deliberante y su relación con el ejecutivo parece ser exacta ${ }^{50}$. Quizás la manera de formular las preguntas - a veces se pregunta para que el encuestado las compare con otras instituciones - hace que las respuestas den una imagen más pobre de la institución, menos valorada. Lo cierto es que hay que situar a las Cortes Generales en un segundo plano en las preferencias de los españoles. Habría que preguntarse qué es lo que determina esta posición de los ciudadanos y cómo se puede corregir. Algo habría que hacer en todo caso, empezando por los propios parlamentarios. En el año 1989, los encuestados, conscientes de la importancia de la institución $-y$ con porcentajes superiores al $20 \%$ de no sabe/no contesta-, consideraban sin embargo en porcentajes importantes que los parlamentarios dedicaban demasiada atención a problemas de poca importancia y representaban poco o nada los intereses de los españoles ${ }^{51}$. Y en 1998 sólo el $40 \%$ de los españoles seguía con mucho o bastante interés a través de los medios de comunicación la información sobre la actividad parlamentaria. Por otra parte, sólo el $58 \%$ se sentía muy satisfecho o satisfecho del funcionamiento del Parlamento español52.

\subsection{El Gobierno de la Nación}

A lo largo de estos 25 años, lo que hace el Gobierno de la Nación interesa menos que lo que hace el Ayuntamiento o la Comunidad Autó-

50 «Este lugar (el del Poder Deliberante) es, a la vez, eminente y secundario. Es eminente, como acabamos de comprobar, en razón de la calidad de las cosas que son deliberadas; es secundario, porque la operación deliberante es un mediocre procedimiento de gobierno. Hemos desenvuelto las razones por las cuales debe atribuirse el primer lugar al poder ejecutivo, y solamente el segundo al poder deliberante; tales razones se resumen en esta sencilla observación: que si el poder deliberante es una excelente fuente de Derecho, pues es la fuente de la ley, es un detestable órgano de gobierno, que no cabe poner al frente del Estado, porque gobernar es obrar, no discutir; por el contrario, el poder ejecutivo es inferior como fuente de Derecho, pero superior como órgano de gobierno, porque es órgano de acción". Hauriou, M., Principios de Derecho público y constitucional, 1927, trad. de Ruiz del Castillo, págs. 473-474.

51 Estudio $\mathrm{ClS}$ n. ${ }^{\circ} 1851$, de diciembre de 1989.

52 Estudio CIS 2309, diciembre 1998. La democracia y sus instituciones. 
noma ${ }^{53}$, pero más que la actividad que desarrolla el Parlamento ${ }^{54}$. Sin embargo - son datos de abril, mayo y julio de $1987-$, el $84 \%$ de los españoles consideraba muy o bastante importante al Gobierno para el funcionamiento de la democracia en España - el Ayuntamiento recibía la misma valoración de parte del $83 \%$ de los encuestados -55 .

Se puede afirmar que, con el paso del tiempo, el Gobierno pasa a un segundo plano y los españoles parecen otorgar más confianza a las instituciones locales y autonómicas.

\subsection{El Poder Judicial}

Las funciones del Consejo General del Poder Judicial son desconocidas por el $62 \%$ de los españoles y su grado de desconocimiento sigue siendo alto cuando se les propone que formulen su acuerdo o desacuerdo con frases que se refieren a sus competencias o a su nivel de eficiencia. Porcentajes que, dada la naturaleza de la institución, no parecen extraños, aunque el Consejo haya sido protagonista de la actualidad con demasiada frecuencia ${ }^{56}$.

Otra cuestión más importante es la orientación de los españoles hacia la administración de justicia, y la confianza que les ofrecen jueces y magistrados. Yo no sé si con elementos de juicio suficientes, cuando se les pregunta sobre qué aspectos de la Constitución deberían reformarse, la Justicia aparece como la más necesitada de mejora ${ }^{57}$. Sin embargo, al ser preguntados los jóvenes españoles sobre el grado de simpatía por determinadas instituciones, los jueces aparecen en posiciones relativas favorables ${ }^{58}$.

A la altura de $1998^{59}$, las respuestas a la pregunta sobre cómo funciona la Justicia en España eran demoledoras: nadie consideraba

53 Estudio CIS 2309, diciembre 1998. La democracia y sus instituciones.

54 Estudio CIS 2309, diciembre 1998. La democracia y sus instituciones y REIS n. ${ }^{\circ} 42$, abril-junio de 1988.

55 Cfr. REIS, $n .^{\circ} 39$, julio septiembre de 1987.

56 Estudio CIS 2309, diciembre 1998. La democracia y sus instituciones.

57 Estudio CIS 2201, diciembre de 1995.

58 Cfr. REIS n. ${ }^{\circ} 52$, octubre-diciembre de 1990.

59 Estudio CIS 2.283. Barómetro de marzo de 1998. Ámbito: Toda España incluyendo las provincias insulares y excluyendo Ceuta y Melilla. Universo: Población española de ambos sexos de 18 años y más. Tamaño de la muestra: 2.497 entrevistas. Error muestral: Error teórico \pm 2 para datos globales, intervalo de confianza del 95,5\% (dos sigmas); para $P=0$, en el supuesto de muestreo aleatorio simple. Fecha de realización: Del 27 al 31 de marzo de 1998. 
que funcionara muy bien, sólo el $10 \%$ pensaba que funcionaba bien, regular el $25 \%$; mal el $39 \%$, muy mal el $18 \%$ y el $8 \%$ no sabía o no contestaba. Sin embargo sólo el $19 \%$ habia tenido relación con la Justicia en los dos últimos años. Quizás ninguna institución ha sido sometida a una crítica tan feroz desde la instauración de la democracia en España. Casi nunca para mejorarla. Las más de las veces para dominarla y politizarla. Se ha hecho una labor irresponsable por parte de los políticos y de la prensa, ignorando la prensa y los políticos que ellos no van a la zaga en el juicio negativo de los españoles. Así, cuando se pregunta a los españoles sobre la confianza en veracidad de ciertos grupos profesionales, los jueces están 30 puntos por encima de Diputados y Senadores y 34 puntos sobre los Ministros del Gobierno y 6 sobre los periodistas. Los líderes sindicales, Diputados y Senadores y Ministros del Gobierno ocupan los últimos lugares en cuanto a confianza en su veracidad. Resultan más creíbles, por ejemplo, la policía, los funcionarios o los sacerdotes. Los jueces ocupan casi lugares de privilegio. Por tanto lo que se piensa es que funciona mal la maquinaria, pero no los jueces como individuos que tienen que juzgar ${ }^{60}$.

Además, a la altura de octubre de 1997 , un $54 \%$ de los españoles prefería ser juzgado por jueces que porTribunales de Jurado, frente a un $32 \%$; el $14 \%$ no sabía o no contestaba. Hay que decir que desde octubre de 1987 la confianza en el Jurado habia caído en un 15\%, hasta el año $1997^{61}$. Y uno se pregunta si la prudencia del legislador no debería haber conducido a no establecer la institución, aunque estuviera prevista como posible en la Constitución.

\section{El Tribunal Constitucional}

En el año 1998, un $56 \%$ de los españoles confesaba no conocer las funciones que desempeña elTribunal Constitucional. Sin embargo, al señalarles cuál de las dos funciones del Tribunal consideraban más

60 Datos de Opinión, n. 2, diciembre de 1995.

61 Demanda de seguridad ciudadana y victimización. Estudio CIS-Dirección General de la Policía 2.200, diciembre 1995-enero 1996. Ámbito: Municipios de más de 50.000 habitantes de las provincias de Alicante, Almería, Asturias, Baleares, Barcelona, Cádiz, La Coruña, Granada, Madrid, Málaga, Murcia, Las Palmas, Pontevedra, Tenerife, Sevilla, Valencia, Zaragoza. Universo: Población española de ambos sexos de 18 años y más. Tamaño de la muestra: 14.994 entrevistas. Error muestral: Para un nivel de confianza del $95,5 \%$ (dos sigmas) y $P=Q$, el error va desde $\pm 2,41$ para la provincia de Madrid hasta $\pm 4,42$ para la provincia de Almería. Fecha de realización: diciembre 1995-enero 1996. 
importantes un $37 \%$ opinaba que evitar que se dicten leyes contrarias a la Constitución y un 35\% amparar los derechos de los individuos frente al Estado. Aun proporcionando esta alternativa, un $28 \%$ decía que no sabía o no contestaba ${ }^{62}$.

\section{Las instituciones autonómicas y locales}

Las respuestas que dan los españoles a las preguntas que se refieren a las instituciones autonómicas y locales acreditan la verdad de las afirmaciones de Alexis de Tocqueville acerca del valor de la vida local en la formación de una conciencia cívica; la idoneidad para generar hábitos de participación a causa de la proximidad de las instituciones al ciudadano ${ }^{63}$. En efecto, los españoles creen que las Autonomías han contribuido a acercar la gestión de los asuntos públicos a los ciudadanos y sirven para atender mejor los problemas propios de cada comunidad, aunque un $40 \%$ piensa en marzo de 1996 que han contribuido al desarrollo de los separatismos a pesar de que, en esas mismas fechas, el $45 \%$ pensaba que habían contribuido a mejorar la convivencia entre las nacionalidades y regiones. Da la impresión de que los españoles son víctimas de los atropellos de los políticos en lo que se refiere al problema autonómico. Tengo para mí que el problema ha sido creado artificialmente por un número escaso de sujetos de mentalidad totalitaria, escaso sentido de la responsabilidad y desprovistos en ocasiones de sentido moral. Lo que quiere decir que si se descargara de tensión política lo que podría ser un buen instrumento de gestión de los asuntos públicos, se habría ganado mucho para la estabilidad del pais. El problema autonómico no deriva - allí donde existede algo que procede de un sentimiento generalizado en la población, surgido espontáneamente, sino de una obstinada influencia ilegítima de la oligarquía de determinados partidos que manejan los mecanis-

62 Estudio CIS 2309, diciembre 1998. La democracia y sus instituciones.

63 «El habitante de Nueva Inglaterra se apega a su municipio, porque éste es fuerte e independiente; se interesa en él, porque participa en su gobierno; lo quiere, porque no tiene que quejarse de sus suerte; coloca en él su ambición y su porvenir; se mezcla en cada uno de los incidentes de la vida municipal; en esa esfera restringida que está a su alcance, intenta gobernar la sociedad; se acostumbra a las formas sin las que la libertad no actúa más que por revoluciones, se penetra de su espíritu, le toma el gusto al orden, comprende la armonía de los poderes, y recoge, en fín, ideas claras y prácticas sobre la naturaleza de sus deberes, asi como sobre la extensión de sus derechos". Cfr. TocouevilLe, A., La democracia en América, traduc. de Marcelo Arroitia-Jáuregui, Gredos, Madrid, 1969. 
mos de control social en su provecho, ignorando la realidad social $y$ la voluntad de los ciudadanos. Sobre todo utilizando el sistema educativo, de forma que en algunos casos ha rayado en lo canallesco, vulnerando los principios educativos contenidos en los documentos internacionales de derechos humanos.

Cuando se pregunta a los españoles sobre sus preferencias acerca de la estructura organizativa del Estado, se observa que desde noviembre de 1984 a marzo de 1996, el número de los partidarios de un Estado centralista baja desde un $29 \%$ al $13 \%$; sin embargo el porcentaje de los que prefieren un Estado con CC.AA. como en la actualidad sube de un $31 \%$ a un $47 \%$; sube también el número de los que prefieren un mayor grado de autonomía - de un $20 \%$ a un $22 \%$ - mientras baja de un $10 \%$ a un $7 \%$ el número de los que verían con gusto el reconocimiento a las comunidades de un derecho a la autodeterminación. Es mayoritario, en marzo de $1996-67 \%$-, el número de los creen positiva la creación de las comunidades autónomas, frente al $13 \%$ que la ven más bien negativa.

En cuanto a la vida municipal, hay que decir que lo que hace el Ayuntamiento es lo que más interesa a los ciudadanos, seguido de lo que hace la Comunidad Autónoma, por delante de lo que hace el Gobierno de la Nación; lo que hace el Parlamento autonómico, nacional o europeo interesa menos $-y$ por ese orden -64 .

\section{Las instituciones sociales}

\section{Los partidos políticos}

En octubre de 1986, al preguntar por la confianza en los políticos en general, sólo un $3 \%$ confiaba mucho en ellos, bastante un $26 \%$, poco un $39 \%$, nada un $17 \%$, no sabía un $10 \%$ y no contestaba un $5 \% 65$.

64 Estudio CIS 2309, diciembre 1998. La democracia y sus instituciones.

65 Barómetros de octubre, noviembre y diciembre de 1986. Ámbito: nacional incluyendo las provincias insulares y excluyendo Ceuta y Melilla. Universo: Población española de ambos sexos de 18 años y más. Tamaño de la muestra: 2.500 entrevistas distribuidas proporcionalmente a la población de los diferentes estratos. Error muestral: para un nivel de confianza del 95,5 por 100 (2 sigma) y $\mathrm{P}=\mathrm{Q}$, el error es de $\pm 2 \%$. Fecha de realización: 16-24 de marzo de 1996. Estudio CIS 2.215. Ámbito: Toda España incluyendo las provincias insulares y excluyendo Ceuta y Melilla. Universo: Población española de ambos sexos de 18 años y más. Tamaño de la muestra: 2.496 entrevistas. Error mues- 
Y sobre los partidos 66 los españoles son conscientes de su necesidad para la existencia de la democracia, para la defensa de ideas o intereses de los distintos grupos y clases sociales - según los términos de la pregunta que se formula en la encuesta-, de su calidad de instrumentos para la participación política, pero también advierten como aspectos negativos su capacidad para dividir a la gente -en el año 1996 el $36 \%$ pensaba que sólo servían para eso - y un $47 \%$ que los intereses que persiguen los partidos tienen poco que ver con la sociedad, y un $38 \%$ que los líderes son más importantes que los programas o que los partidos se critican mucho entre si pero en realidad son todos iguales -57\%-67. La imagen que los ciudadanos tenían en el año 2000 no había mejorado en absoluto. En ese año sólo un 6\% pensaba que los partidos tienen en cuenta la opinión de los ciudadanos ${ }^{68}$.

\subsection{Los sindicatos}

Cuando en 1994 se preguntaba a los españoles sobre los sindicatos, decian por mayoría muy amplia que se trababa de organizaciones desfasadas, politizadas y que ofrecían poco a sus afiliados. El $70 \%$ de los encuestados pensaba que no debían intervenir en política y limitarse a los problemas estrictamente laborales. Y más de la mitad de los españoles decía que las opiniones de los líderes sindicales no eran representativas de las de los trabajadores y que cada vez lo eran menos. Los encuestados progresivamente iban comprendiendo que los intereses de los sindicatos $y$ de los empresarios eran en parte opuestos $y$ en parte los mismos ${ }^{69}$.

\subsection{Las empresas}

A la altura del año 2000, las empresas merecían más confianza a los españoles que los sindicatos, por ejemplo, y que el sistema judi-

tral: Error teórico \pm 2 para el conjunto de la muestra. Fecha de realización: 19 a 22 octubre 14 a 19 de noviembre y 16 a 18 de dciciembre 1986.

66 Barómetro de abril, mayo y julio 1987, . $^{\circ}$ Estudios 1626, 1654 y 1695.

Fecha: Abril, mayo y julio 1987. Tamaño: $2.476,2.490$ y 2.493, respectivamente. Universo: Población española, ambos sexos, 18 y más años. Ámbito: nacional Aspectos metodológicos: Entrevista personal.

67 Datos de opinión $n .^{\circ} 5$ (series históricas del CIS) junio de 1996.

68 Estudio CIS 2.387. Cultura política. Barómetro de marzo, citado.

69 Estudio CIS 2.088, julio 1994 
cial, aunque esa confianza se situaba por debajo de otras instituciones lo suficientemente heterogéneas como para no sacar conclusiones demasiado seguras. Diría que la valoración se mueve en un grado de normalidad si tenemos en cuenta los porcentajes que alcanzan otras instituciones. En todo caso, la imagen de los sindicatos y clase empresarial no era la creada por ciertos partidos en la transición y los años inmediatamente siguientes ${ }^{70}$.

\section{Los problemas sociales}

Desde el Barómetro de septiembre de 1979 el paro, el terrorismo y el orden público y la seguridad ciudadana son los problemas que más preocupan a los españoles ${ }^{71}$. En 1995 los problemas más importantes eran: a) paro; b) corrupción; c) agricultura, ganadería, pesca y sequía; d) mala labor del gobierno; e) crisis económica; f) terrorismo; g) drogas; h) inseguridad ciudadana y por este orden.

En 1998, al preguntar a los españoles sobre cuáles eran los tres principales problemas sociales, colocaban el paro (85\%) a más de 30 puntos sobre el siguiente, que era el terrorismo $(52,7 \%)$; iba detrás la droga y el alcoholismo $(29,1 \%)$, delincuencia y seguridad ciudadana $(13,8 \%)$, a los que seguían problemas económicos y el funcionamiento de los servicios públicos ${ }^{72}$.

A la altura del mes de abril de 2003, al formular la misma pregunta (repuesta espontánea), colocaban en primer lugar el paro, seguido del terrorismo, la inseguridad ciudadana, la vivienda, problemas políticos, problemas económicos, drogas e inmigración $n^{73}$. El paro y la inseguridad ciudadana eran los problemas que más incidían personalmente en los encuestados según sus respuestas.

Es decir, que los problemas sociales en España desde la aprobación de la Constitución son los mismos, con ligeras variantes en su formulación y en la posición que ocupan en orden a su gravedad; se han convertido en problemas estructurales, permanentes.

70 Estudio CIS 2.443. Religión y sociedad, citado.

71 Barómetro de septiembre de 1979, REIS n. ${ }^{\circ} 7$.

72 Barómetro de julio de 1998. Estudio 2.294.

73 Estudio CIS 2.508, abril 2003, citado. He prescindido de la opinión sobre la guerra de Irak por ser una cuestión absolutamente coyuntural. Situaban el problema detrás de la inseguridad ciudadana. 


\section{A MODO DE CONCLUSIÓN}

Uno de los detalles que llama la atención al comparar las últimas encuestas con las que se publicaron, por ejemplo, en el n. ${ }^{\circ} 2$ de la REIS es que ha decrecido en términos generales el número de los que no saben o no contestan. Y esto es una buena señal. La gente tiene menos prevención ante preguntas que tienen que ver con cuestiones políticas o tienen formada opinión sobre los asuntos públicos en mayor medida que en aquellos años. Me parece que hay que empezar destacando esta realidad que denota más confianza, más libertad de ánimo, mayor interés por las cuestiones políticas aunque haya en esto cierto déficit.

En segundo lugar, la existencia de un acuerdo sobre el acierto de la transición, obra de todos pero sobre todo del conjunto de los españoles. Este sentir como obra propia el proceso constituyente y el producto del proceso: la Constitución. Efectivamente muchos dicen no conocerla en lo que tiene de texto jurídico, pero sabe la inmensa mayoría qué significa tener una Constitución: tener más libertad.

Han comprendido que la democracia, también con las deficiencias en su realización concreta, es la mejor forma de organizarse políticamente. Se ha consolidado la monarquía como forma política del Estado y quien viene encarnando la Jefatura del Estado ha suscitado la adhesión generalizada de los españoles, y esto era muy importante de cara a la estabilidad de la institución.

Con todas las deficiencias que juristas y políticos han señalado al funcionamiento del Estado Autonómico, la organización territorial del Estado ha calado en el conjunto de la población, y los problemas que a veces se plantean se deben al comportamiento errático de los gobernantes aunque los que los padezcan sean siempre los ciudadanos. La vida local se ha hecho más rica. El ciudadano percibe el municipio como algo cercano. Siente que su influencia es más decisiva aquí que en otros ámbitos.

El español ha ido adquiriendo, con todas las limitaciones evidentes, cualidades positivas para una vida política más intensa. Esto era lo importante.

Sin embargo, hay aspectos negativos que deberían ser corregidos entre todos. La mayoría de esas deficiencias tienen que ver con la pérdida de la dimensión moral de la política, que no es más que la manifestación concreta de una crisis de dimensiones más amplias. La democracia, la Constitución, las instituciones son comprendidas en su valor 
real para la vida social en cuanto categorías; pero el parecer sobre el funcionamiento efectivo o sobre el comportamiento político concreto es más bien negativo.

No debería perderse nunca de vista que la política es también una paideia, una pedagogía. Por eso al gobernante no le es ajena una labor de mejora del ciudadano. No puede inhibirse situándose en una neutralidad que, por serlo, es dañina para la misma existencia de la democracia. Debe recobrarse el sentido clásico de la política y de la comunidad política como realidades que deben contribuir a la mejora del hombre como persona. La democracia es un procedimiento, pero también es una substancia. Tiene un contenido que, si no queremos vaciarla de sentido, hay que intentar enriquecer sin desnaturalizar. Suele citarse -y me parece un acierto que se haga - la oración fúnebre que Tucidides pone en boca de Pericles, donde se da una magnífica definición de la democracia como forma de vida y también como forma política ${ }^{74}$. Volver a los orígenes suele ser siempre provechoso si se tiene suficiente criterio para distinguir lo que constituye un valor permanente de lo que es accidental, y por tanto sujeto a los cambios de históricos.

La sociedad, como conjunto de los grupos sociales en que se integran los individuos, debe asumir sus responsabilidades en relación con la existencia de una vida democrática digna de ese nombre. Y la organización del Estado no debe hacer del art. 9.2 un instrumento de dominio, de aherrojamiento de la energía social, sino de servicio a cualquier iniciativa social compatible con la Constitución y factible desde las posibilidades del Estado en cada caso.

Hay deficiencias innegables en nuestro sistema político y en el comportamiento de los que tienen que darle vida. Algunas arrancan desde el inicio mismo del cambio político y otras las hemos acumulado a lo largo de estos años. Algunas graves. Pero a pesar de todo quizás podríamos aplicar a esta nueva aventura constitucional -que esperemos dure muchos años - las palabras que Calderón puso en boca del Rey en la escena final de El alcalde de Zalamea, cuando enjuiciaba la conducta de Pedro Crespo:

\section{que errar lo menos no importa si acertó lo principal. ${ }^{75}$}

74 Cfr. Tucídides, Historia de la guerra del Peloponeso, Libro II, 37 y ss.

75 Cfr. CALDERón DE LA BARCA, P., El alcalde de Zalamea (1636). ed., introduc. y notas de Domingo Yndurain, Planeta, Barcelona, 1982. 